\title{
Clean Heat and Power from Solid Fuels - Modern Approaches
}

\author{
HANASOGE S MUKUNDA \\ CGPL, Indian Institute of Science, Bangalore 560 012, India
}

(Received on 30 March 2014; Accepted on 02 August 2015)

\begin{abstract}
This article is concerned with the science and technology of the conversion of solid fuels such as coal and bio-residues (wood, agricultural and urban solid wastes) into a clean combustible gas that drives gas turbines or reciprocating engines at a variety of power levels. Large coal gasification systems employ high pressure reactors along with gas treatment to enable the gas to be used in combined cycle mode with gas turbines and heat recovery steam generators. A review of the international experience suggests that these are very expensive in the Indian context and have not found their way despite many efforts over the last three decades. Alternative strategies involving flameless combustion/gasification at medium power levels (10-50 MWe) needing development are discussed here. Biomass wastes form a large sector for utilization and by the nature of their properties and availability are most suited for small power generation (a few thousand $\mathrm{kg} / \mathrm{h}$ or equivalently a few MWe). All solid biomass waste is expected to be processed to eliminate extra organic material (sand, grit, etc.) and brought to regular shape, size and high density $\left(700\right.$ to $1000 \mathrm{~kg} / \mathrm{m}^{3}$ ) to facilitate thermal conversion process in fixed bed high temperature reactor at moderate oxidant (air) fluxes to produce combustible gas having $\mathrm{CO}, \mathrm{H}_{2}, \mathrm{CH}_{4}$ and inerts. The gas is cooled (usually) and cleaned of particulate matter and any sulphur-related compounds before being used for heat or electricity generation. Fuel-to-electricity conversion efficiencies of $27 \%$ to $30 \%$ for small power and up to $35 \%$ at medium power levels can be achieved. The strategy allows the lowest possible emissions with unit investment costs comparable to large power systems. Recognition and encouragement for these routes will add significant value to the national effort on heat and power generation.
\end{abstract}

Keywords: Energy Conversion of Solid Fuels; Gasification of Solid Fuels; Combustion of Solid Fuels; Clean Combustion; Coal and Biowaste Conversion

\section{Introduction}

Clean conversion of solid fuels to useful energy which is different from the classical approach involves producing combustible gas that can generate better or multiple outputs - (a) better conversion efficiency from fuel to electricity $\left(\eta_{f e}\right)$, (b) reduced gaseous emissions of $\mathrm{CO}_{2}, \mathrm{SO}_{\mathrm{x}}$ and $\mathrm{NO}_{\mathrm{x}}$, apart from complex heavy metals in the ash stream, (c) $\mathrm{CO}_{2}$ capture so that as much of carbon can be sequestered into useful products for societal need or stored in the earth or under the sea and (d) electricity combined with chemicals (Maurstad, 2005; Parthasarathi, 2009; Intnet 1, 2012).
Better conversion efficiency implies reduced use of the solid fuel and a reduction in the corresponding emissions. Beyond this, reduction in $\mathrm{SO}_{\mathrm{x}}$ and $\mathrm{NO}_{\mathrm{x}}$ calls for the introduction of specific unit operations into the flow path; $\mathrm{SO}_{\mathrm{x}}$ is to be converted to sulphur or sulphuric acid and $\mathrm{NO}_{\mathrm{x}}$ should be converted to $\mathrm{N}_{2}$ to the extent possible. Further reduction in $\mathrm{CO}_{2}$ is caused by separating it from the flue gases and using it as a chemical reactant to produce other substances of importance, such as for instance silica from sodium silicate or storing it deep underground or under the sea. In order to aid the separation process, air is replaced partially or completely by oxygen. This leads

*Authorfor Correspondence: E-mail: mukunda@cgpl.iisc.ernet.in 
Table 1: Combustion or gasification process outputs for coal/biowastes

\begin{tabular}{llllll}
\hline Oxidizer & Reaction products & Pollutants & Output & Pressure & Comments \\
\hline Air & $\mathrm{CO}_{2}, \mathrm{H}_{2} \mathrm{O}, \mathrm{N}_{2}$ & $\mathrm{SO}_{\mathrm{x}}, \mathrm{NO}_{\mathrm{x}}$ & Heat, electricity & Ambient & Combustion-steam generator \\
$\mathrm{O}_{2}$ & $\mathrm{CO}_{2}, \mathrm{H}_{2} \mathrm{O}$ & $\mathrm{SO}_{\mathrm{x}}, \mathrm{NO}_{\mathrm{x}}$ & Heat, electricity & Ambient & Oxy-fuel combustion \\
Air & $\mathrm{CO}_{2}, \mathrm{H}_{2}, \mathrm{CH}_{4}$ & $\mathrm{H}_{2} \mathrm{~S}, \mathrm{NH}_{3}$, & $\begin{array}{l}\text { Heat, electricity, } \\
\text { chemicals }\end{array}$ & High/ambient & $\begin{array}{l}\text { Gasification to producer gas; high } \\
\text { pressure - IGCC plant }\end{array}$ \\
& $\mathrm{CO}_{2}, \mathrm{H}_{2} \mathrm{O}, \mathrm{N}_{2}$ & Tars & Heat, electricity, & High/ambient & Gasification to Syngas, IGCC and/or \\
$\mathrm{O}_{2}$-steam & $\mathrm{CO}_{2} \mathrm{H}_{2}, \mathrm{CH}_{4}$, & $\mathrm{H}_{2} \mathrm{~S}, \mathrm{NH}_{3}$, & $\begin{array}{l}\text { liquid hydrocarbons } \\
\text { chemicals }\end{array}$ \\
\hline
\end{tabular}

(Adapted from Klass, 1998; Mukunda, 2011)

to the oxy-fuel process. It is possible to add steam to the process to generate combustible gases rich in $\mathrm{CO}$ and $\mathrm{H}_{2}$. This gas can be used as a feedstock for conversion to liquid hydrocarbons through the familiar Fischer-Tropsch process (Maurstead, 2005; Parthasarathi, 2009).

When one moves from combustion to gasification (as it happens in two lower rows of Table 1), (i) the products change largely into combustible gases, and (ii) the pollutants change their character as well. Further, the outputs can be multiple - one can design the process to obtain chemicals as well (Table 1). For instance, if one uses coconut shell as a fuel, we can design a gasifier that produces $30 \%$ char and heat for steam generation and subsequent power or steam for activation leading to activated charcoal (Mukunda, 2011). This can replace the existing pit method to produce charcoal and therefore yield multiple benefits. Rice husk is a fuel used in fluidized bed boilers to produce high pressure steam for electricity generation. The residue is black char that has about $10 \%$ to $15 \%$ carbon and $20 \%$ ash (with respect to rice husk as reference); the ash has $95 \%$ precipitated silica. In addition to electricity generation, it is possible to obtain precipitated silica and activated carbon (about 5\% to $7 \%$ of the rice husk mass). Also, $\mathrm{CO}_{2}$ in the exhaust can be used to produce precipitated silica. This is perhaps the most integrated approach in generating renewable energy (Mukunda, 2011).

Section 2 describes the solid fuel usage in India - coal and biomass, and section 3, the properties of these fuels; these form the background for the technology description to follow. Section 4 addresses the distinguishing features of combustion and gasification as a part of thermal conversion process, the basic processes of which are explored in section 5 ; the critical aspects of gasification are delineated in section 5.1. Section 6 discusses the conceptual technological features of systems from other countries for coal and also presents the status in India. Gasification technologies for small and medium scale power levels are discussed in section 7. The final section discusses the way forward.

\section{Fuel usage in India}

Coal is an important fuel source used for generation of electricity. As the number of steam power plants increases to meet the increasing demand, so does the use of coal in excess of $550 \mathrm{mmt}$ (million metric tonnes) in 2012 (Mukunda et al., 2010). Solid biofuels in the form of firewood, agricultural residues and dried cowdung are used in cooking in over 120 million households to a total of $420 \mathrm{mmt}$. While coal used in power stations leads to fuel-to-heat efficiencies, $\eta_{f h}$ of $75 \%$ to $85 \%$ (with accompanying fuel-to-electricity efficiencies, $\eta_{f e}$ of $35 \%$ to $36.5 \%$ ), biomass used in domestic stoves occurs with utilization efficiencies, $\eta_{u}$ of $10-20 \%$ that is composed of $\eta_{f h}$ of $30 \%$ to $50 \%$ and heat transfer efficiency, $\eta_{h t}$ of $35 \%$ to $40 \%$ ( $\eta_{u}=$ $\eta_{f h} \eta_{h t}$ ) (Mukunda, 2011). The use of biomass wastes occurs in small thermal power stations with $\eta_{f h}$ of $60 \%$ to $70 \%$ as the combustion system has to accept fuels of varying shapes, sizes, moisture and ash content. 
Coal contains impurities that affect emission performance also. While Indian coals contain a small amount of sulphur which on combustion leads to acidrain forming sulphur dioxide, they are also laden with large amount of inorganic material leading to high ash fraction (of up to $40 \%$ ). Imported coals from Australia and Malaysia have lower ash content but larger amount of sulphur that needs to be dealt with to limit the emission of sulphur oxides.

\section{Properties of Fuels}

To appreciate the critical aspects of the thermal conversion process, it is important to examine the properties of the fuels considered as shown in Table 2. The density of coal is large and that of biomass varies widely. Coal is used in the form of sized pieces on a grate or in a pulverized form in special injection systems. Biomass is used either in as-received form of agro-residues or in processed form as firewood, or densified into pellets or briquettes with a mix of agroresidues. While the as-received form of biomass can consist of moisture up to $50 \%$, sun-drying condition reduces it to about $10 \%$. The lowest ash content in biomass occurs with wood or some agro-residues such as coconut shell. The largest ash fraction occurs with rice husk and rice straw $(\sim 20 \%)$; other agroresidues have ash content $<5 \%$. The ash content of urban solid waste should largely be $<10 \%$ allowing for a small amount of pickup of sand, grit and mud due to the inclusion of sweepings. However, the pickup can be as large as $50 \%$ and it is necessary to process the urban solid waste to shed the pickup and reduce the ash content. Coal is produced because of natural biomass processing at high pressure and temperature deep inside the earth. This is why (a) biomass whose volatile content is $\sim 75 \%$ loses a large part to be reduced to about $30 \%$, (b) density increases (to 1200$1500 \mathrm{~kg} / \mathrm{m}^{3}$ ) even after the loss of volatiles reducing the active mass by $50 \%$, and (c) the amount of ash depends on the geological history of the process with some regions adding only a few percent and others adding large amounts. Owing to some of these features, the calorific value of some coals is not very different from biomass.

\section{Features of Combustion and Gasification}

The energetic parts of coal and biomass are made up of carbon and hydrogen elements which are to be converted to carbon dioxide and water vapour in the combustion process. The amount of air required for this purpose varies from 6 to $10 \mathrm{~kg}$ per $\mathrm{kg}$ fuel. Thus, the gaseous products are 7 to 11 times the fuel consumption rate. The presence of undesirable emissions in the products implies that a large throughput of the product gas needs to be handled if their fraction has to be brought down. An alternative process would be to convert the solid fuels into fuel gas by a process known as gasification which is essentially an aero-thermo-chemical process more intricate than combustion. The amount of air required for the conversion is about $20 \%$ to $25 \%$ of the air required for complete combustion -about 1.5 to 2 times the fuel throughput. Thus, the fuel gas flow rate will be 2.5 to 3 times the solid fuel throughput.

Table 2: Properties of typical solid fuels

\begin{tabular}{lllllll}
\hline Fuel & $\rho, \mathrm{kg} / \mathrm{m}^{3}$ & $\mathrm{f}_{\text {ash }}, \%$ & $\mathrm{f}_{\text {moisture }}, \%$ & Shape/size & $\mathrm{LCV}, \mathrm{MJ} / \mathrm{kg}$ & $\mathrm{f}_{\mathrm{volt}}, \%$ \\
\hline Coal, Lignite & $\sim 1200$ & $5-30 *$ & $5-20$ & Pulverize or size & $15-25$ & $20-40$ \\
Sized wood pieces & 300 to $600<1$ & $\begin{array}{l}10 \text { sundry), } \\
50 \text { (green) }\end{array}$ & Can be sized & 16,9 & $\sim 80$ \\
Agricultural residues, woody & As above & $<1$ & As above & Can be sized & As above & $\sim 70$ \\
Agricultural residues, leafy & 50 to 150 & $4-20$ & As above & Varying, needs densification & $14-10$ (sundry) $60-65$ \\
Urban solid waste & $\sim 250$ & $<10$ & As above & Same & Similar & $\sim 70$ \\
\hline
\end{tabular}

$\rho=$ density,$f_{\text {ash }}=$ ash fraction, $f_{\text {moisture }}=$ moisture fraction, $L C V=$ Lower calorific value, $f_{\text {volt }}=$ volatile fraction, $f_{\mathrm{fc}}=$ fixed carbon, $* B y$ MoEF (Govt. of India) order, coal washeries should be used to ensure coal that transported to power plants beyond $1000 \mathrm{~km}$ from pithead should have $\mathrm{f}_{\text {ash }}<34 \%$. (Adapted from Klass, 1998; Mukunda, 2011) 
Alternatively stated, the fuel gas flow rate is about a third to half of the final burnt products. Any treatment process of this gas to limit the presence of undesirable products is performed with less expense since the amount to be treated is much less for the same fuel throughput. What more, the gas so produced that is composed of $\mathrm{CO}, \mathrm{H}_{2}, \mathrm{CH}_{4}$, (the three combustibles) $\mathrm{CO}_{2}$ and $\mathrm{H}_{2} \mathrm{O}$ (inerts) in proportions that depend on whether the fuel is biomass or coal and the actual conversion process used, typically with active combustible matter amounting to $50 \%$ is capable of being used in gas turbines or reciprocating engines for electricity generation. Further, with the thermal energy left behind in the exhaust gas, it will be possible to operate a steam cycle as well. Thus, the $\eta_{f e}$ of the combined cycle works out to $40 \%$ to $42 \%$. This operation called integrated gasification combined cycle (IGCC) constitutes the essence of "clean power". Thus, with the use of the gasification technologies, one can obtain higher efficiency and lower emissions at justifiable extra costs. The oxidizer used in classical power plants is air.

The more interesting point is that the gasification process can be introduced even for domestic cook stoves (at thermal power levels of 3 to $4 \mathrm{~kW}$ ) raising the $\eta_{u}$ to upwards of $45 \%$ (up to $65 \%$ in community kitchen size stoves with power levels of $15 \mathrm{~kW}$ ) because it is possible to achieve $\eta_{f h}$ of $90 \%$ to $92 \%$ through the gasification process and heat transfer efficiencies of more than $50 \%$.

\section{How Does Combustion of Coal and Biomass Proceed?}

Much more is known about combustion of coal as it is widely practised. When large pieces of coal (5 to $50 \mathrm{~mm}$ size) have to be burnt, it is done on a grate. A bed of burning coal moves on a travelling grate inside a furnace. The rate of travel is so adjusted that most of the coal would have burnt off by the time the end is reached. Air is allowed to flow through the bed and also introduced over the bed. After initial heating to bring up the entire furnace to over $600^{\circ} \mathrm{C}$ at which condition, radiation and convection cause ignition of an incoming coal particle and allow it to be burnt through the travel over the grate. This process consists of release of moisture initially and then volatiles which burn up in the gas phase. During the rest of the travel period, the coal char burns up largely with heterogeneous reactions between the oxidant-oxygen in the air and surface carbon. The effectiveness of this process is controlled by the amount of ash, the magnitude of which is higher due to loss of some active material in terms of volatiles. The carbon conversion fraction in this process may not be the highest since some large particles may be dropped off before all the carbon in them is fully oxidized. In large size systems, fluidized bed combustion is also practiced. The coal particles remain in suspended form surrounded by air and other hot products and burn up with efficiencies better than on grate. Achieving this calls for limiting the size of the coal particles to a narrower range.

In order to achieve better combustion efficiency $\left(\eta_{f h}\right)$, coal is pulverized to 70 to 100 microns and burnt in pulverized fuel burners. Combustion is much better in such systems because the particle size is much smaller and it burns in a suspended state surrounded by hot oxidizer-rich products. Most of this is diffusionlimited combustion both in the volatile and char oxidation modes.

Combustion of solid biomass whether it is a stove or a furnace occurs largely in a diffusion mode with the flame surrounding the particle or a firewood stick. The volatile regime for biomass is much more vigorous and energy carrying than for coal since the volatile fraction is much higher. Combustion of fine particulate matter such as sawdust or leafy matter occurs with volatile release taking a very short time (less than a few seconds utmost) and the char may or may not get oxidized unless the environment is sufficiently hot and oxygen-rich.

Since the rate processes in large-scale systems handling coal or biomass become less efficient than theoretical expectations, the air flow that must be provided will need to be higher, slightly or not-so slightly depending on the design and operational features so that the emissions of undesirable gases is limited. This is described as excess air ratio that varies between $10 \%$ and $30 \%$; it ensures better oxidation, reduction 
of the emission of undesirable intermediate products of combustion and the power required for the blower. In the case of internal combustion engines such as gas turbines, the combustion process has to meet other requirements of compactness of the combustion chamber with appropriate wall cooling and causing required dilution of hot gases to provide the set turbine inlet temperature and profile.

\subsection{What is Critical about Gasification?}

Two questions arise: what is so different about gasification compared to combustion? How come, there are so many different approaches to gasification when such variability does not exist for combustion?

The important distinguishing feature in gasification is that the entire conversion process must be conducted with oxidant flow rates about a quarter of that for combustion. This implies that the conversion of volatiles itself will be at around stoichiometry for coal, but very rich for biomass, this distinction is due to the fact that volatile fraction in coal is about a third of that in biomass. In fact, a simple distinction between coal and biomass would be that the process is largely coal-char centered for coal and volatile-centered for biomass. The first process is termed oxidative pyrolysis or flaming pyrolysis to distinguish this from the classical pyrolysis process that occurs in the complete absence of oxidant. Gases emanating from the volatile conversion process will contain some unconverted products such as $\mathrm{CO}$, poly-aromatic hydrocarbons (PAH) and other oxygenated compounds apart from $\mathrm{CO}_{2}$ and $\mathrm{H}_{2} \mathrm{O}$. The latter two complex compounds that have a condensation temperature of $50-250^{\circ} \mathrm{C}$ are called tars. Those that condense at higher temperatures are called heavy tars and others, light tars. All biomass gasification technologies are seriously concerned with producing near-tar-free gas. Classical updraft systems (see later) including coal have copious amounts of tar in the gas and need extensive treatment if they have to be used in engines for power generation; most usually, they are contemplated for thermal applications and Europe has many industries supplying biomass and coal systems up to $100 \mathrm{t} / \mathrm{h}$ capacity.

Producing clean combustible gas demands thermo-chemical reactions of the products of oxidative pyrolysis, $\mathrm{CO}_{2}$ and $\mathrm{H}_{2} \mathrm{O}$ and the complex chemicals (PAH and other oxygenated compounds) with char. These reactions are essentially reducing in nature and so endothermic; the rate is strongly dependent on temperature as also the reactivity of the char. Fig. 1 shows the reaction of various fuels as a function of temperature. Normally, the reaction rate varies with temperature following the Arrhenius law: $r_{m} \sim \exp$ $(-E / R T)$, where $E$ is the activation energy and $E / R$ is called the activation temperature and this is the reason that the plot has $\ln \left(r_{m}\right)$ vs. $1 / T$. It is clear from the plot that among chars, biomass char has the highest reactivity and pet coke the lowest. Lignite and coal lie in between the two.

Experiments have shown that char per sé can reduce the tars apart from converting $\mathrm{CO}_{2}$ and $\mathrm{H}_{2} \mathrm{O}$ to simpler compounds and $\mathrm{CO}$ and $\mathrm{H}_{2}$. It is important that sufficient residence time in the high temperature range be allowed to enable the final composition reach near-equilibrium conditions. Such a condition ensures the breakdown of the complex compounds to simpler ones. The complex compounds are classified as "tar" - heavy and light (the distinction of heavy and light is made depending on the condensation temperature). The concern for the presence of the tars is that when the gases are cooled, they will deposit in the passages and other difficult-to-access locations. The magnitude of the tars will be between 0.1 and $10 \mathrm{~g} / \mathrm{nm}^{3}$ of the gas. In large throughput systems, the magnitude of the tar generated in some designs (such as updraft and fluid bed systems to be discussed later) is so large that collection and management of the tars itself is an

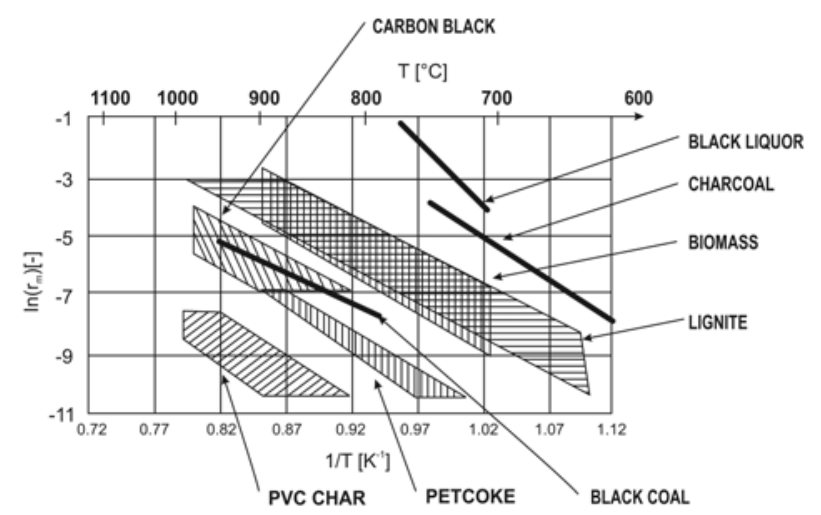

Fig. 1: Reactivity of various fuels (drawn from Parthasarathi, 2009) 
issue unless the magnitude is limited by design. This issue is even more important for electricity generating systems using reciprocating engines since the valve seatings have small passages and deposition has been known to occur in these passages. Thus, the efficiency of gasifier design is measured by gasification efficiency (which is the ratio of the energy contained in the gas to that of the fuel) and the simplicity of design in reducing the magnitude of the tars. If the design is complex, the operability of the system becomes compromised due to either a heavy load on instrumentation for monitoring the operation or enhanced maintenance.

\section{Gasification Technologies}

Gasification technologies can be classified into those meant for large and small systems. This distinction almost completely covers the differences between coal and biomass systems. Much more has been written about large coal gasification systems and even a cursory internet browsing will reveal description of these systems and their performance; a number of international conferences on clean coal technologies seem to be taking place biannually (intnet1, 2012).The four major commercial gasification technologies in order of decreasing capacity installed are (a) SasolLurgi (Dry Ash), South Africa, (b) Shell, (c) GE (originally developed by Texaco) and (d) ConocoPhillips E-gas (originally developed by DowChemicals).

The Sasol-Lurgi gasifier (developed by Lurgi) has gained extensive commercial experience at the synthetic fuel plants in South-Africa.The design is of the fixed bed and non-slagging type (ash is dry). The other three gasifiers belong to the entrained flow slagging (ash is melted and extracted) type. Shell and GE-Texaco gasifiers have considerable commercial experience with gasification, while ConocoPhillips has less experience. Still, the three companies GE, Shell and ConocoPhillips are all perceived as major players with respect to future IGCC projects which concentrate on entrained flow slagging gasifiers.

Fluidized bed gasifiers are less developed than the two other gasifier types. Operating flexibility is more limited for this class of gasifiers because of the need to perform several functions (e.g. fluidization, gasification and sulphur removal by limestone injection) with limited design flexibility (for example, the air blown KRW fluidized bed gasifier was not able to start up successfully in projects during 1998 to 2000). Fig. 2 shows the features of three designs of high pressure gasifiers. Of these, the Pratt and Whitney design is undergoing development and hence is not discussed any further here (see Maurstad, 2005 and Fusselman et al., 2006, for more details).
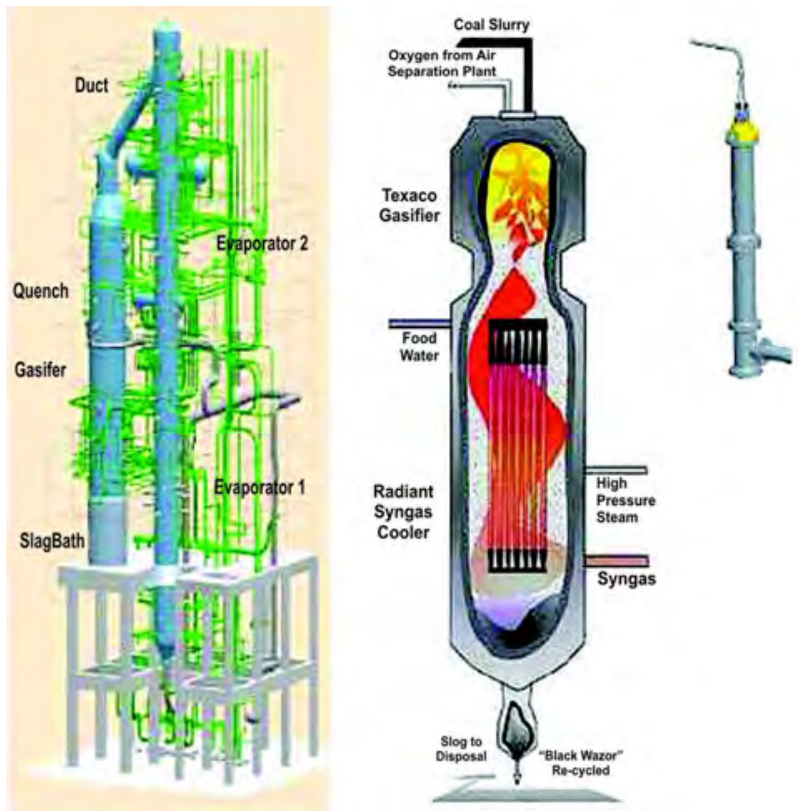

Fig. 2: Three designs of high pressure coal gasification systems. Left: hell design; Middle: GE design and Right: Pratt and Whitney rocket-based design (adapted from Fusselman et al., 2006)

There are several options for many elements of the current working IGCC system as shown in Table 3. The pressurized entrained-flow Shell gasifier uses a dry-coal feed and 95\% pure oxygen (from an air separation unit) to produce a medium heating value fuel gas. The syngas produced in the gasifier at about $1700 \mathrm{~K}$ is quenched to around $1200 \mathrm{~K}$ by cooled recycled syngas. Then, the gas passes through a convective cooler and leaves at around $600 \mathrm{~K}$. Highpressure saturated steam is generated in the syngas cooler and is joined with the main steam supply. Raw gas leaving the syngas cooler is cleaned of particulate matter and passes through a COS (carboxy-sulphide) 
Table 3: Design element features for various high pressure gasification technologies (Maurstad, 2005)

\begin{tabular}{|c|c|c|c|}
\hline $\begin{array}{l}\text { Technology/ } \\
\text { Design feature }\end{array}$ & Shell & GE-Texaco & E-Gas (Conocophillips) \\
\hline Feed system & $\begin{array}{l}\text { Dry coal, lock hopper }+ \\
\text { pneumatic conveying }\end{array}$ & Coal-in-slurry (65:35) & Coal-in-slurry $(65: 35)$ \\
\hline Gasifier configuration & Single stage entrained up-flow & Single stage down-flow & Two stage up-flow \\
\hline Gasifier wall & Membrane wall & Refractory & Refractory \\
\hline Pressure (atm) & $<45$ & $<45$ & $35-70$ \\
\hline $\begin{array}{l}\text { Composition of the gas } \\
\text { cooled to } 25^{\circ} \mathrm{C}, \% \mathrm{v}\end{array}$ & $\begin{array}{l}\mathrm{CO} \sim 58, \mathrm{H}_{2} \sim 30, \mathrm{~N}_{2} \sim 8, \mathrm{CO}_{2} \\
\sim 2, \mathrm{Ar} \sim 1, \mathrm{H}_{2} \mathrm{~S} \sim 0.21, \mathrm{COS} \sim 0.02 \\
\text { Others* } \sim 0.01\end{array}$ & $\begin{array}{l}\mathrm{CO} \sim 40, \mathrm{H}_{2} \sim 40, \mathrm{~N}_{2} \sim 2, \\
\mathrm{CO}_{2} \sim 15, \mathrm{Ar} \sim 2, \mathrm{COS}+\mathrm{H}_{2} \mathrm{~S} \sim \\
0.3, \text { Others } * 0.2\end{array}$ & $\begin{array}{l}\text { Composition similar to } \\
\text { GE -Texaco system }\end{array}$ \\
\hline Observations & With heat recovery & Quench or with heat recovery & With heat recovery \\
\hline
\end{tabular}

*Others at trace levels: $\mathrm{HCN}, \mathrm{NH}_{3}, \mathrm{HCl}, \mathrm{NH}_{4} \mathrm{Cl}, \mathrm{Ni}(\mathrm{CO})_{4}, \mathrm{HF}, \mathrm{Pb}, \mathrm{Hg}, \mathrm{As}, \mathrm{Fe}(\mathrm{CO})_{5}$, etc.

hydrolysis reactor before entering a Sulphinol-M acid gas $\left(\mathrm{H}_{2} \mathrm{~S}\right)$ removal process. Elemental sulphur is produced as a salable byproduct. The clean gas is conveyed to the combustion turbines where it serves as fuel for the combustion turbine/heat recovery steam generators (HRSG)/steam turbine power conversion system.

The features of GE-Texaco gasifier vessel are described in Table 3. Coal-water slurry is transferred from the slurry storage with a high-pressure pump. At the top of the gasifier vessel is located a combination fuel injector through which coal slurry feedstock and oxidant (oxygen) are fed. The high temperature reactor operates at around $1600 \mathrm{~K}$ to produce syngas. Hot syngas and molten solids from the reactor flow downward into a radiant cooler where the gas is cooled to $800 \mathrm{~K}$ and the ash solidifies. Raw syngas continues downward into a quench system and then into a syngas scrubber for removal of entrained solids. The gas goes through a series of gas coolers and cleanup processes including a COS hydrolysis reactor, a carbon bed mercury removal system, and a Selexol acid gas removal plant $\left(\mathrm{CO}_{2}\right.$ and $\mathrm{H}_{2} \mathrm{~S}$ ). Slag captured by the syngas scrubber is recovered in a slag recovery unit. Regeneration gas from the acid-gas removal plant is fed to a Claus plant, where elemental sulphur is recovered. Humidification of the syngas and nitrogen dilution helps in minimizing formation of $\mathrm{NO}_{\mathrm{x}}$ during combustion in the gas turbine burner section. The gas composition lends itself also as a feedstock for chemicals such as hydrocarbons through Fischer-Tropsch process. One of the drawbacks of the composition is that the desired $\mathrm{H}_{2}$ :CO of 2:1 is not fulfilled here. Gas separation may be needed to obtain the right composition. A key feature of the high pressure-high temperature reactors is that there is very little tar-related problem largely because they run on oxygen.

Gaseous emissions from the gasification systems are presented in Table 4. Higher conversion efficiency to electricity implies the need for lesser fuel for the same output. This reduces the amount of $\mathrm{CO}_{2}$ emitted. The significant difference in emissions between advanced technologies and classical technologies in practice for power generation in India is evident in Table 4. While the advanced technologies are more expensive (per unit capacity installed), their inherent worth in being environment friendly is clearly obvious. The gas clean-up costs are reduced through the choice of oxygen as the oxidant because this increases the concentration of $\mathrm{CO}_{2}$ in the gas enabling its removal before use for power generation. In the choice of fuels for these systems, biomass is factored in so that the issue of reduction in carbon footprint is better addressed. The central problem is that biomass in as-received form has very high moisture and when this is reduced the densities are about a third of coal. This implies that the volumes to be handled are very 
Table 4: Comparison of the performance of various gasification technologies (Parthasarathi, 2009)

\begin{tabular}{lcccccl}
\hline Technology & $\begin{array}{c}\eta_{e}, \\
\%\end{array}$ & $\begin{array}{c}\mathrm{SO}_{\mathrm{x}} \\
\mathrm{mg} / \mathrm{kWh}\end{array}$ & $\begin{array}{c}\mathrm{NO}_{\mathrm{x}} \\
\mathrm{mg} / \mathrm{kWh}\end{array}$ & $\begin{array}{c}\mathrm{PM}, \\
\mathrm{mg} / \mathrm{kWh}\end{array}$ & $\begin{array}{c}\mathrm{CO}_{2} \\
\mathrm{~g} / \mathrm{kWh}\end{array}$ & Waste/by-products, g/kWh \\
\hline AFBC* ${ }^{*}$, steam-turbine & 36 & 1400 & 800 & 100 & 774 & Gypsum = 20, Fly-ash =25 \\
PC $^{+}$- Steam-turbine & 36 & 2500 & 2300 & 300 & 852 & Nearly same as above \\
GE-Texaco, IGCC & 41 & 130 & 350 & 20 & 745 & Same as above \\
Shell-Siemens, IGCC & 43 & 100 & 50 & 20 & 712 & $\mathrm{~S}=4$, Fly-ash $=2$, Slag $=220$ \\
NGCC - reference & 56 & 7 & 540 & 20 & 350 & None \\
\hline
\end{tabular}

*Ambient pressure fluidized bed reactor, ${ }^{+}$Pulverized coal combustor, $\mathrm{NGCC}=$ Natural gas combined cycle

large. This makes the inclusion of biomass problematic in power plants that handle over a million tonnes per year of coal even at the level of $10 \%$ of biomass inclusion. Therefore, the inevitable valid conclusion in Western countries is that biomass plays a weak role in large-scale electricity generation. The question of relevance is: which advanced coal technology is appropriate for India?

\subsection{Indian Technologies on IGCC}

BHEL (Trichy) has taken an initiative in developing the know-how at 6.2 MWe and gained experience on its operations. A visit to the facilities and technical exchange on the fundamentals associated with the design features (intnet2, 2012) showed that several conversion-related aspects needed reconsideration. Beyond this, the office of the Principal Scientific Advisor to the Prime Minister tried to develop a 125 to $180 \mathrm{MWe}$ IGCC project for India (intnet3, 2015). However, there has been no progress on ground eight years after the effort. IGCC is often considered an advanced area and many intricate aspects of the technology are held close to the chest by the overseas technology holders making it difficult for others to access. A true impediment is that the cost of the technologies is high-going up to Rs. 1000 crores (2 billion USD) for a meaningful project of 100 to 150 MWe) with uncertainties of high ash coals not addressed adequately. If IGCC class of technologies has to be developed, it is important to find an alternative path that does not involve large first investment cost and risk perception. The latter is possible with enough fundamental research and demonstration on a plant at some appropriate scale. New pathways and their foundations are described below.

\section{Technology and the Basis for Small Plants - Biomass and Coal}

Biomass gasification technologies are usually designed for smaller power levels - typically less than a few MWe. This is because of the sustainable availability of biomass for the expected life of the plant. In both USA and Canada, there are large biomass-based power plants of medium capacity - 20 to $50 \mathrm{MWe}$. In countries such as India, land holdings are small $(\sim 1$ ha per family) and sourcing waste biomass from plantations or agricultural residues is a significant issue. The price at which the biomass is available at the plant site will vary with season and on a year-to-year basis to such an extent that it is only the power plants based on captive bio-waste that can be expected to function. Rice husk based power plants in some Indian states in India (such as Chattisgarh) have functioned well. Even though a large number of steam power plants based on agricultural residues at power levels of 4 to 10 MWe have been built, many of them function at suboptimal conditions and some have been closed as well, all because the year-to-year projected biomass procurement price levels were substantially exceeded later. In fact, even at present, several power plants of over 10 MWe are being conceived and investments made without fully realizing the implications of the sustainability of biomass.

This situation can be averted if one contemplates the choice of gasification technologies that have unit 
power levels of 1 to $2.5 \mathrm{MWe}$ since the annual requirement of fuels will be in the range of 10 to 20 thousand tonnes per year. If biomass availability allows larger power levels, the use of multiple units can be contemplated without loss of economy of scale since the cost per MWe reaches saturation at around a MWe level. Through the use of ambient pressure gasifier and the promise of clean gas for use in high grade heat, chemical feedstock or electricity at throughput levels requiring a few $\mathrm{kg} / \mathrm{h}$ to a few $\mathrm{t} / \mathrm{h}$, one can at the least create solutions towards the possibility of overcoming problems noted earlier. The power generation system will be based on reciprocating engines rather than gas turbine engines. When it comes to the use of coal, the economic power level will need to be raised to at least $10 \mathrm{MWe}$ in an IGCC mode with reciprocating engines for the principal electricity generation and the exhaust heat for heat recovery steam-power generation (HRSG). This conceptual frame research is new and needs explanation. A conventional IGCC depends on gas turbines. The open cycle efficiencies $\left(\eta_{f e}\right)$ are typically $30 \%$ and the HRSG adds another $10 \%$ to $12 \%$. In the case of reciprocating engines in excess of $500 \mathrm{kWe}, \eta_{f e}$ is nearly $28 \%$ to $35 \%$ with HRSG adding about $8 \%$ to $9 \%$ to a total of $36 \%$ to $44 \%$. The recovery from the steam route is less than that of gas turbines because the electricity-to-heat ratio is higher for reciprocating engines than gas turbines. It is important to recognize that gasification process for biomass has been studied in India far more intensively than in the rest of the world for over three decades at the laboratory and in the field with extensive inputs from one to the other that India can rightfully claim leadership in this area.This understanding should also benefit the coal gasification at medium throughputs (1-3 t/h). Scaling to $10-50 \mathrm{t} / \mathrm{h}$ coal technologies needs new ideas and will be discussed below.

\subsection{Biomass Gasification Technologies}

Section 5.1 has already dealt with the steps involved in gasification. Much research has been performed in India with the financial support from the Ministry of New and Renewable sources of Energy. All the research over the last three decades on this subject by the author and colleagues can be found in Mukunda
(2011). The core of the technology lies in the aerothermo-chemically controlled reactor-fluid flow effects, heat and chemistry determine the quality of the hot gas generated. While the effects of heat and chemistry has been well-appreciated in design over the last 50 years, the fluid flow effects have been treated so empirically over this time that progress has occurred in the recent past in elucidating these effects; these have been integrated into the modern design. The principal reactor designs are atmospheric pressure fixed bed updraft and downdraft. In an updraft reactor (Fig. 3A), air flows from the bottom upwards through a packed bed of sized biomass pieces which moves downward as biomass gets gasified (the gas is extracted at the top region) leaving behind the ash that is extracted from the bottom; this is a counterflow feature. In a closed top downdraft design (Fig. 3B), air and sized biomass pieces move down together. Both gas and ash are drawn off and extracted from the bottom region. In the case of updraft system, complete char oxidation with air occurs first. Then, the hot gases get partly converted to producer gas in reaction with the char layers above and move through the biomass bed. This process causes the release of volatiles and hence the gas that exits from the reactor has the maximum amount of condensable tars, typically about $10 \mathrm{~g} / \mathrm{nm}^{3}$; this magnitude is also roughly matched by fluidized bed gasifiers in which the pathway from solid particles to gas is not systematic; no intersection of the gas with char particles is assured. As such, its behavior is similar to fixed bed updraft systems. Thus, both these systems are suitable only for thermal applications. Any attempt to deploy them for electricity generation via reciprocating engines requires such an expensive, elaborate cleanup system that it will be practically impossible to maintain the operations in a satisfactory manner. Fixed bed downdraft systems of World War II origin are always closed top. This practice is maintained even these days by most designs. A different design using open top first discussed by Thomas Reed (see Mukunda, 2011for details) was combined with the side air nozzles of other designs to obtain results that neither of them can provide. To understand this, it is necessary to study the principles of the new design developed and patented by Indian Institute of Science (Mukunda, 
2011). Fig. 3C shows the schematics of the reactors of the open top (staged air ingestion) IISc downdraft design. The best way to understand the processes occurring inside this reactor would be to examine the operation in two extreme modes: Air drawn from the top with side air nozzles closed and air drawn from the side air nozzles by keeping the top closed (to simulate in part the closed top design).

It is to be first understood that all gasifiers work by converting biomass to char which further participates in the reduction reactions to generate combustible gas; as such, the reactor is loaded with char up to the height of the air nozzles (in both cases) for the first time and biomass on the top that will be topped up on usage. The system is started by introducing a high temperature torch to the side air nozzles. Since most gasifier designs adopt a suction mode of operation with a blower downstream drawing off the gas downstream, the hot gases of the torch will light up the char inside the reactor. In a few minutes, the entire char bed is lit. Now, the air nozzles are closed and air ingestion from the top is allowed. The processes that occur in the bed cause flame propagation to the top at 100 to $200 \mathrm{~mm} / \mathrm{h}$. Once the flame reaches the top, the entire reactor will be filled with char. Beyond this point, the operation will switch to char mode and the reactor cannot accept any more biomass. Such an operation is unacceptable unless char is continuously extracted at the rate at which it is generated (typically $30 \%$ ). Even if this is arranged, the gas that is generated has a significant tar, up to 1 $\mathrm{g} / \mathrm{nm}^{3}$ and this needs to be brought down to the lowest possible level. This is brought down by opening the side air nozzles so that air flow is shared between the top and the side nozzles, typically around 70:30 ratio. The air from the side air nozzles burns up the flaming pyrolysis products again in the rich mode, a process called re-burn. This maintains the bed temperature making the high temperature zone much broader than that of the closed top design. The broader temperature profile helps the char-gas reactions to reduce the tar level to the lowest possible level and maintain a good composition at the exit. The flame front can be restricted to a small zone above the side air nozzles, a feature that helps maintaining a steady operational behaviour. A further problem that occurs with agricultural residue based biomass is the problem of ash fusion that is caused because the ash fusion temperature gets lowered due to the presence of potassium. This problem has been faced with straw burning furnaces as well the world over. A straightforward way of overcoming this would be to

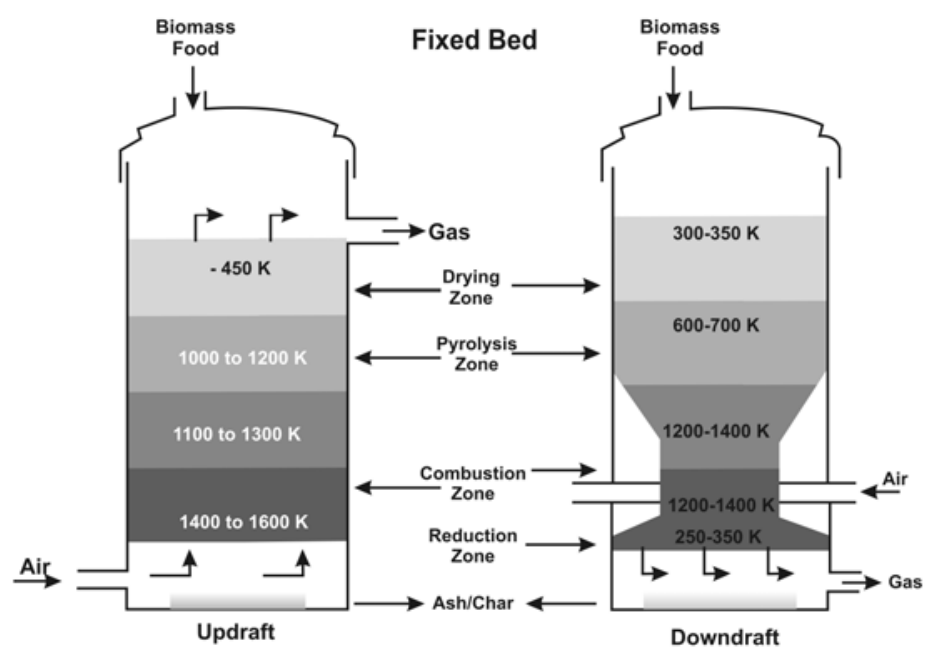

A

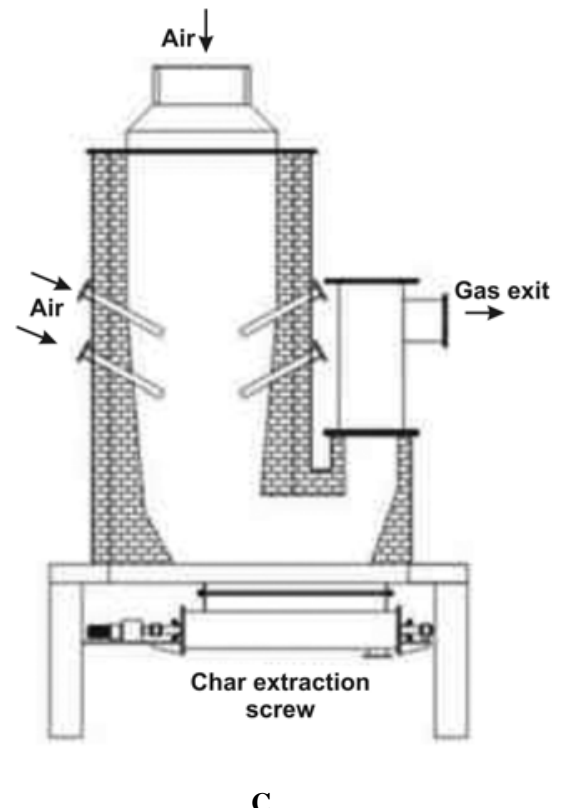

Fig. 3: Fixed bed gasifier reactor schematics - updraft (A), closed top downdraft (B) and open top downdraft (C) (drawn from Mukunda, 2011) 
densify the material into briquettes of 50 to $100 \mathrm{~mm}$ size. This reduces the contact points between materials reducing the ash fusion possibilities and the high density will help the downward movement of the material. Thus, biomass preparation and the possibility of staged air ingestion help in allowing multi-fuel option, a feature very essential for seasonally available agroresidues. One of the key issues is related to the management of the high temperature zone that is both oxidizing and reducing in different zones. While some designers have used thick mild steel, more advanced designs have used ceramic tiles. The structure is composed of high alumina (>75\% alumina) tiles on the innermost face with hot-face and cold face insulation bricks next to it to ensure that the outer temperatures are limited to acceptable industrial environment values (see extreme right in Fig. 2). The presence of high alumina tiles is crucial to avoid ash fusion with the wall material, something that can happen if the alumina content is lower.

This technology has performed with changes of fuel from coconut shell to Prosopis julifora and back to coconut shell in a $1000 \mathrm{~kg} / \mathrm{h}$ powering a $1 \mathrm{MWe}$ (4 $\times 250 \mathrm{kWe}+1 \times 250 \mathrm{kWe}$ ) Cummins engine system for over three years with total operating hours exceeding 18,000 hours; the changes in fuel occurred because during a period, a disease struck the coconut plantations reducing the availability of coconut shells with accompanying price rise to such levels that the fuel cost was equal to the tariff paid by the utility. More about the experiences is discussed in Mukunda (2011).

\subsubsection{Domestic Cooking}

A way of using gasification idea for a low thermal power ( 3 to $500 \mathrm{kWth}$ say) has been evolved from ideas discussed above - of ensuring a flaming pyrolysis zone first and a hot char bed through which these gases pass through so that even if "tar" conversion is not complete, it does not affect the combustion that occurs almost immediately afterwards. Fig. 4 shows two designs that have been conceived and built. The first of the designs is essentially reverse of the downdraft gasifier (Fig. 4 top; Mukunda et al., 2010). Air supply is from the bottom and the top of the packed fuel bed is lit and the flame propagates downwards converting biomass to char and the hot gases pass through the char bed to produce combustible gas. This design has also been termed TLUD (Top Lit UpDraft) in literature (Mukunda, 2011). One can construct a horizontal gasifier by creating a draft of air through the bed and ensuring that the gases from flaming pyrolysis pass through a char bed. This is enabled by providing the air supply system in interrupted struts between which gases can flow. Fig. $3 \mathrm{C}$ and D shows the smallest stove for $1 \mathrm{~kg} / \mathrm{h}$. Similar ideas have been used to build industrial stoves up to $150 \mathrm{~kg} / \mathrm{h}$. Typical flame temperatures are 1200 to 1600 $\mathrm{K}$ (larger power systems are close to the higher temperature) maintaining oxygen fraction in the hot stream of $1 \%$ to $3 \%$. This also ensures minimal emissions of $\mathrm{CO}$ let alone PAH and other compounds.

\subsubsection{Medium-Scale Coal Gasification}

Medium-scale coal gasification is a subject on the horizon not of relevance to advanced countries. It is of importance to India where procuring capital for "risky" projects is only through government and this route has not been successful for over two decades.

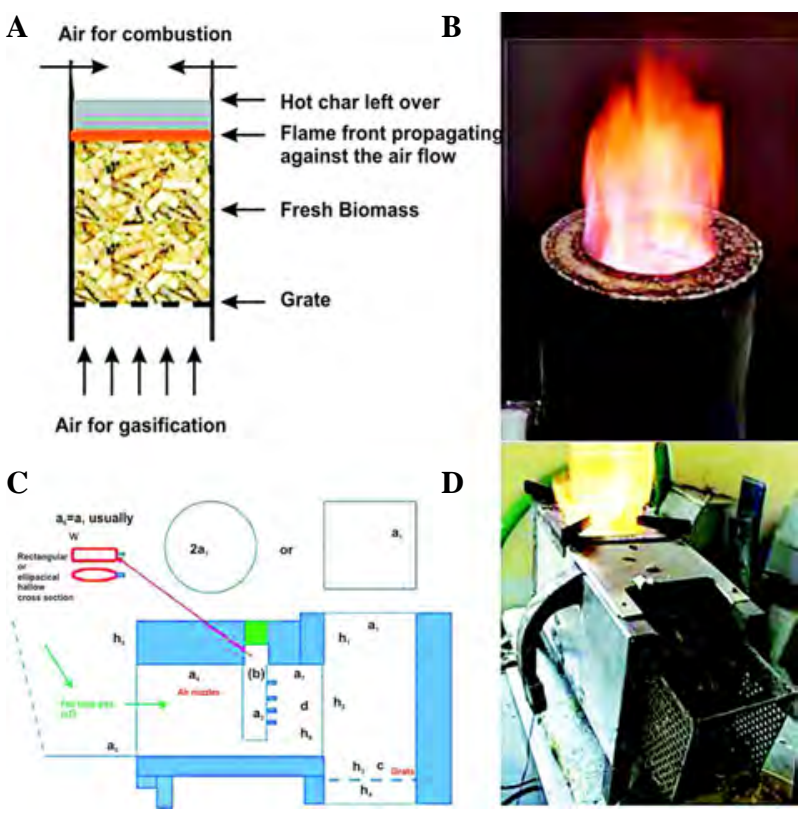

Fig. 4: Two classes of gasifier stoves.Principles of gasification-combustion (A), the combustion quality (B), Horizontal gasifier design for multiple fuel sizes and types (C) and combustion quality (D) 
This requires new ideas that have been tried out for "flameless" combustion studied (for instance, Kumar et al., 2002), developed and practiced for gases to obtain high efficiency with minimal emissions (particularly of $\mathrm{NO}_{\mathrm{x}}$ ) and pulverized coal (Fu et al., 1986), both of which have been tested and proved at ambient pressure. The essential idea here is to separate the injection of fuel and oxidant streams and provide them at high velocity. The high velocity causes entrainment of the product gases that heats up as well as dilute both the streams till a point that the jet temperatures cross about 1300-1400 K when autoignition of the mixed streams is possible. This reduces the range of operating temperatures of the combustor (from 1300 to $2100 \mathrm{~K}$ instead of 300 to $2100 \mathrm{~K}$ ) that is now considered similar to "stirred reactor". This reduces the pressure fluctuations and acoustic signature of the combustor and the flame structure is very transparent due to heavy recirculation (of about 2 to 3 ) of hot gases inside. Fig. 5 shows the expression of these ideas in coal combustors. Use of this approach reduces the dependence on oil for flame stabilization. These ideas can be extended to gasification either with air or oxygen. The hot gases from the gasifier can be processed in cooling and cleaning system, ideas for which can be drawn from biomass gasifier system development that have already reached commercial maturity.

The gases now are ready for induction into any engine. It is possible to create design options with multiple engines of $2.5 \mathrm{MWe}$ running on one or more gasifiers. Further, combined cycle operation is possible using exhaust heat based steam cycle. The benefit from such an approach is the scaling down of the

A

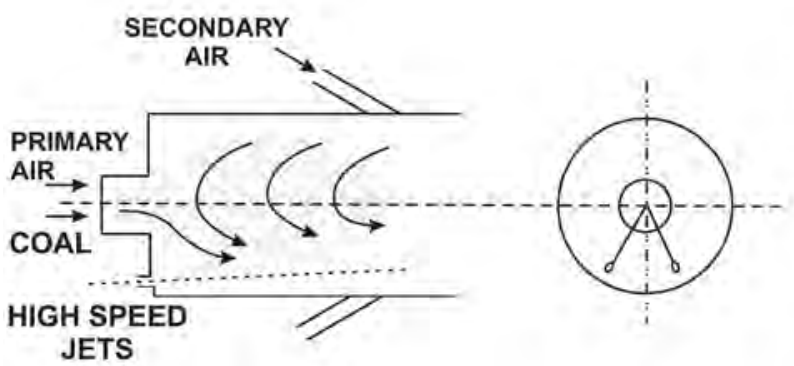

IGCC ideas into economical lower capacity systems. Simple cycle calculations show that typically $20 \mathrm{MWe}$ IC engine power and 3 to 5 MWe HRSG power need an investment of less than $2500 \mathrm{USD} / \mathrm{kWe}$ (intnet3, 2015). These form the ideas for future research and development.

\section{The Way Forward}

Handling solid fuels is admittedly more difficult than gaseous or liquid fuels. The scientific attention paid to the conversion of solid to gaseous fuels has been inadequate. If one examines the approach that India or a few other developing countries need, it becomes clear that one needs to add to the basket of technologies, medium scale coal gasification solutions, biomass gasification technology for energy and chemicals and small-scale biomass-based heating devices. One most important feature is that there is severe scarcity of affordable solid biofuels in many areas of the country. Hence, it would be necessary to combine the research on efforts in liquid biofuels that generate significant solid wastes, other tree wastes and urban solid waste to produce substantial amounts of solid fuels in standard shapes, sizes and ash fraction, declare their properties and make them available similar to liquid or gaseous fuels. If this is combined with mature technologies for solid fuel use for heat at the domestic level as well as semi-industrial level, it will take much economic pressure off from the dependence on gaseous fuels that have become very expensive. This approach has the intrinsic advantage of being environment friendly, a feature that makes economic imperative consistent with environmental imperative.

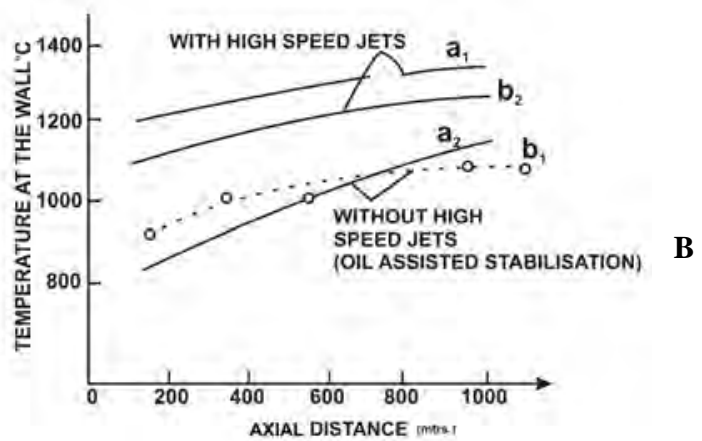

Fig. 5: Principle of flameless combustor-gasifier for gases being adopted for coal (A) and its performance in actual operation (B) (Fu et al., 1986) 
In the case of coal technologies, it is necessary to encourage more scientific working groups, especially from a younger generation to enable new ideas to flower into products. Encouraging this research is not entirely easy as the broad area has remained outside the active interest of most scientific groups for over three decades and hence special request for proposals has to be made outside of

\section{References}

Fu W, Wei J B, Zhan H Q, Sun W C, Zhao L, Chen Y L, Han H Q, Huang W S and Wu C K (1986) The use of coflowing jets with large velocity differences for the stabilization of low grade coal flames Proc Comb Inst 21 pp 567-574

Fusselman S P, Sprouse K M, Darby A K, Tennant J and Stiegel G J (2006) Pratt \& Whitney Rocketdyne/DOE Advanced Single-Stage Gasification Development Program www. netl.doe.gov/technologies/coalpower/gasification/ gasifipedia/pdfs/PCC_Paper_final061305.pdf; Jeffrey Hoffmann, Jenny Tennant, and Gary J. Stiegel. Comparison of Pratt and Whitney Rocketdyne IGCC and Commercial IGCC Performance, Final Report, DOE/ NETL-401/062006

Intnet1 (2012) IEA Clean Coal Centre in UK, papers from 2009 Conference, http://www.cct2009.org/ibis/iea-cct-2009/myevent

Intnet2 (2012) Principal Scientific Advisor's office, GoI's presentation in 2005, http://psa.gov.in/writereaddata/ 11913302011_IGCC.pdf traditional coal agencies to bring in freshness to the approach. Supporting such groups financially should not be a difficult task since similar class of finances is made available to researchers in other fields; a significant part of this must be supported with relatively clear end points rather than blue sky research.

Intnet3 (2015) http://cgpl.iisc.ernet.in

Klass D L (1998) Biomass for renewable energy, fuels and chemicals. Elsevier Inc

Kumar S, Paul P J and Mukunda H S (2002) Studies on a new high-intensity low-emission burner Proc Comb Inst $\mathbf{3 0}$ pp 1131-1137

Maurstad O (2005) An overview of coal based Integrated Gasification Combined Cycle (IGCC) Technology, http:// sequestration.mit.edu/pdf/LFEE_2005-002_WP.pdf

Mukunda H S, Dasappa S, Paul P J, Mahesh Y, Ravi kumar D and Mukund D (2010) Gasifier stoves - Science, technology and field outreach CurrSci 98 pp 627-638

Mukunda H S (2011) Understanding clean energy and fuels from biomass. Wiley India Pvt Ltd also see number of scientific and field performance-related documents (and another book:Biomass to Energy - The Science and Technology, IISc Bio-energySystems)

Parthasarathi D (2009) Reliance Industries limited, IGCC invited lecture, pdpu.ac.in/downloads/Clean\%20Coal\%20 Technology.ppt 